\title{
PERCEPÇÃO DA (AUTO)IMAGEM GERACIONAL PELOS JOVENS DE ENSINO MÉDIO DE TEIXEIRA DE FREITAS/ BA, PELA TÉCNICA DOS MAPAS MENTAIS
}

\author{
Emerson da Silva Mendes ${ }^{1}$ \\ Lilian Reichert Coelho ${ }^{2}$
}

Resumo: O presente trabalho objetivou compreender a percepção do/as jovens de Teixeira de Freitas/BA sobre o município onde residem. Nesse sentido, o problema de pesquisa efetivou-se a partir do questionamento sobre os modos como os/as jovens moradores/as de diferentes bairros da cidade de Teixeira de Freitas/BA constroem suas subjetividades em relação ao espaço urbano e como percebem a alteridade em relação a outros/as jovens. Como procedimentos metodológicos, utilizamos a técnica de análise da produção de mapas mentais, além da realização de entrevista coletiva. Concluiu-se que a juventude teixeirense explora de forma segregatória os espaços abrangidos pelo território, seja com base nos índices de violência que insistem em permear as relações sociais, criando ruídos onde poderia haver troca e diálogo, seja por experiências pregressas que vivenciaram.

Palavras-chave: Imagens de si. Território. Juventude. Subjetividades.

Abstract: This paper intended to comprehend the perception of young people of Teixeira de Freitas/BA about the city where they live in. The research problem centered on the questioning about the ways young people from different neighbourhoods of Teixeira de Freitas construct their own subjectivities in relation with the urban space and how they construct the otherness. In regard of methodological procedures, we used the analysis technique of mental maps production, besides the accomplishment of collective interviews. We concluded

\footnotetext{
${ }^{1}$ Discente do Programa de Pós-Graduando Lato Sensu em Gênero e Sexualidade na Educação pela Universidade Federal da Bahia (UFBA); Graduação em andamento no Curso de Bacharelado em Direito pela Universidade Federal do Sul da Bahia; Bacharel Interdisciplinar em Humanidades pela Universidade Federal do Sul da Bahia (2017).

2 Docente da Universidade Federal do Sul da Bahia; Doutora em Letras (Literatura Contemporânea) pela Universidade Federal da Bahia (2009); Mestra em Estudos Literários pela UNESP-Araraquara (2000); Graduada em Comunicação Social/Jornalismo pela Universidade Estadual de Londrina (1998);
} 
that the youth of Teixeira de Freitas explores the expanded space of the territory in a segregated way, whenever it is based on violence data that insist to cross social relations, creating white noise where it could have had trade and dialogue, or by previous experiences they have lived.

Keywords: Self Images. Territory. Youth. Subjectivities.

\section{Introdução}

O município de Teixeira de Freitas, localizado no Extremo Sul Bahia, às margens da BR-101, a aproximadamente $700 \mathrm{~km}$ da capital, Salvador, configurou-se ao longo dos anos como cidade-polo da região por meio de vertiginosas transformações. Isso ocorreu devido, sobretudo, ao acentuado processo migratório para a região, notadamente a partir de 1989, com a implantação de uma fábrica de papel e celulose (KOOPMANS, 1993). O município foi emancipado no dia 9 de maio de 1985 de Alcobaça e Caravelas.

Um distinta característica que caracteriza o município de Teixeira de Freitas/BA é proximidade com dois grandes rios, Itanhém e Alcobaça, cuja contribuição para o crescimento da cidade e desenvolvimento econômico é significativamente peculiar. A respeito de tais aspectos, o historiador ROCHA (2015: s/p), pondera que:

Sua população configurava-se por pequenas comunidades rurais, em sua maioria negra, localizada à beira dos rios supracitados. A configuração geográfica de Teixeira de Freitas era composta por florestas atlânticas, matas e brejos. A principal forma de locomoção e interação entre as comunidades era o meio fluvial, que utilizavam os trechos navegáveis dos rios e/ou trilhas abertas no meio da mata.

Nas últimas décadas, o município de Teixeira de Freitas/BA revelou, em seu Produto Interno BrutoPIB, significativa parcela de contribuição das empresas de agricultura e pecuária que se instalaram na região do sul baiano. Essa tendência de monoculturas e grandes propriedades tem provocado danos ambientais $\mathrm{e}$ sociais de difícil reversão.

Extraímos de observações aos indícios verificados em material midiático de recorte local/regional e por observação simples, direta e pública, em situação natural (FLICK, 2009: 204) das falas de diferentes moradores da cidade, que o município é percebido como lugar topofóbico (TUAN, 1980) para os/as jovens devido à violência urbana, cujos 
agentes seriam, prioritariamente, jovens dos bairros periféricos.

Diante disso, a pesquisa se propôs compreender e analisar a percepção e a construção subjetiva dos/as jovens de Teixeira de Freitas/BA sobre o município onde residem, orientando-se pela investigação dos modos como são construídas discursivamente as relações eu-nósoutros pelos/as jovens moradores/as de diferentes bairros da cidade de Teixeira de Freitas/BA.

O projeto foi desenvolvido entre os anos de 2015 e 2016 com estudantes do Ensino Médio do Colégio Estadual Henrique Brito, localizado na rua Ministro Mario Andreazza - SN, no bairro Teixeirinha, Cidade de Teixeira de Freitas, Estado da Bahia. O colégio possuía, à época, de acordo com o portal da Secretaria de Educação do Estado da Bahia, cerca de 668 alunos regularmente matriculados e recebeu investimento de cerca de 1 milhão, 746 mil e 890 reais por ano.

Como técnica de análise, foi empregada a dos mapas mentais ou cognitivos, que, a partir das representações expostas em forma de desenhos pelos/as participantes, possibilita derivar informações para a elaboração e aplicação de oficinas. As oficinas proporcionaram verificar de que modos os sujeitos da pesquisa constroem a (auto)imagem geracional.

\section{Procedimentos Metodológicos}

Com o objetivo de investigar os modos como a juventude teixeirense pensa a violência urbana em Teixeira de Freitas-BA, aplicou-se, de forma aberta, num período de dois meses, um questionário online. $\mathrm{O}$ instrumento de pesquisa foi construído por meio de um formulário eletrônico via Google Drive e divulgado em grupos diversos, assim como em página pessoal dos/as envolvidos/as nesta pesquisa da rede social Facebook. Ao fim da aplicação, chegou-se a um resultado de 71 - setenta e uma - respostas.

No que diz respeito ao recorte do grupo social pelo viés etário, sublinha-se a dificuldade de se definir juventude como categoria genérica ou universal, pois, como todas as classificações, é marcada por uma historicidade inerente. CURY (2009: 90) destaca que, "até pouco tempo a juventude era vista, no Brasil, apenas como uma fase de transição da adolescência para a vida adulta. Em função do próprio Estatuto da Criança e 
do Adolescente (ECA) as políticas para o segmento estavam restritas ao universo de jovens com idade até dezoito anos." Ainda sobre a realidade brasileira, ANDRADE e RODRIGUES (2008: 102) explicam que:

Diante do processo histórico de prolongamento da experiência juvenil na vida das pessoas (começando cada vez mais cedo e terminando cada vez mais tarde), o governo brasileiro decidiu adotar, para a definição de políticas públicas de juventude, uma faixa etária abrangente: 'a juventude (...) congrega cidadãos e cidadãs entre os 15 e os 29 anos (...). Nesse caso, podem ser considerados jovens os adolescentes-jovens (entre 15 e 17 anos), os jovens-jovens (entre $18 \mathrm{e}$ 24 anos) e os jovens-adultos (entre 25 e 29 anos).

Compreendendo a amplitude dessa discussão, optou-se por seguir a tendência oficial, pois julgamos oferecer um espectro variante de sujeitos, o que possibilita mais diversidade para $\mathrm{o}$ trabalho.

Posteriormente à tabulação e análise dos resultados provenientes da aplicação dos questionários, foi estabelecida a criação de um grupo focal para a execução da técnica de análise dos mapas mentais. Após contato por meio de ofício com três Colégios da Rede Estadual de Educação, tivemos retorno positivo do Colégio Estadual Henrique Brito onde, após apresentação do projeto
76

à coordenação administrativa, iniciamos

o processo de sensibilização e mobilização da comunidade para a participação nas atividades futuras.

A fim de convidar a comunidade estudantil a colaborar com esta pesquisa de forma estritamente voluntária, planejamos, junto com a direção administrativa do Colégio, 02 (dois) momentos presenciais com os/as estudantes. O primeiro teve por objetivo explicar de forma detalhada a proposta da pesquisa, seus objetivos, metodologia e finalidades. No segundo momento, foram entregues àqueles/as estudantes que previamente já haviam manifestado interesse em colaborar com o trabalho os Termos de Consentimento Livre e Esclarecido. Importante destacar que a participação não foi restrita a pessoas de uma série/ano específico; pelo contrário, a diversidade aqui se apresenta como traço relevante para o desenvolvimento da pesquisa e seus resultados.

Para estreitar os laços e manter comunicação contínua com os/as jovens que aderiram à proposta e facilitar as trocas de informações com relação às atividades que seriam desenvolvidas, criamos um grupo na rede social Whatsapp exclusivo para finalidades acadêmicas. Um dado surpresa que 
emergiu das etapas preliminares foi $\mathrm{o}$ fato de que discussões sobre temas transversais à pesquisa e que atravessam a dinamicidade dos sujeitos sociais logo surgiram de forma natural $\mathrm{e}$ enriqueceram o desenvolvimento das atividades ligadas ao projeto. Sustenta-se tal fato na sob a hipótese de que o ambiente digital proporciona interação descentralizada entre os indivíduos, o que permite o diálogo horizontal entre pares.

Após constituição do grupo de participantes, foram realizados 04 (quatro) encontros presenciais, todos previamente planejados e divulgados aos/às participantes, ocorridos nas dependências da Universidade Federal do Sul da Bahia, Campus Paulo Freire. Nessas ocasiões, foram desenvolvidas rodas de diálogos, exibições de curtasmetragens/documentários, seguidas de discussões, prática de desenhos, produções textuais e atividades que visavam à compreensão sobre a percepção dos/as participantes em relação ao território e as condições e situações que o atravessam.

O primeiro encontro, ocorrido no dia 17 de março de 2016, foi planejado, inicialmente, para ter três momentos: o primeiro foi destinado à reapresentação da proposta e do objetivo da pesquisa para esclarecimento de eventuais dúvidas e mobilização dos afetos mútuos. Em seguida, exibiu-se o curta-metragem "Por trás de um rótulo" (2015), produzido por estudantes do Projeto Curta Jovem. Posteriormente, foram realizadas discussões a partir de um roteiro de perguntas abertas orientadas pelos/as pesquisadores/as sobre rótulos sociais, desejos, anseios, autopercepção, trabalhados no curtametragem, sempre correlacionando com as vivências do grupo na cidade de Teixeira de Freitas/Bahia.

Por fim, foi solicitado aos/às estudantes que elaborassem um trabalho individual - mapa mental - no qual representassem visual, graficamente, seu território. A equipe compartilhou com os/as jovens participantes algumas definições de território, dentre as quais a de Raffestin, que o entende "[...] a partir do espaço, é o resultado de uma ação conduzida por um ator sintagmático (ator que realiza um programa) em qualquer nível. Ao se apropriar de um espaço, concreta ou abstratamente [...] o ator “territorializa” o espaço". (RAFFESTIN, 1993: 143).

$$
\text { Já SANTOS (1978: 171) }
$$
conceitua território como “[...] O espaço 
por suas características e por seu funcionamento, pelo que ele oferece a alguns e recusa a outros, pela seleção de localização feita entre as atividades e entre os homens, é o resultado de uma práxis coletiva que reproduz as relações sociais."

Ao término das atividades do primeiro encontro, foi solicitado que os/as jovens apresentassem seus trabalhos ao coletivo, a fim de identificar e compreender as representações produzidas, assim como as justificativas associadas às escolhas dos elementos representados. Os mapas foram recolhidos pela equipe com permissão dos/as participantes para posterior análise.

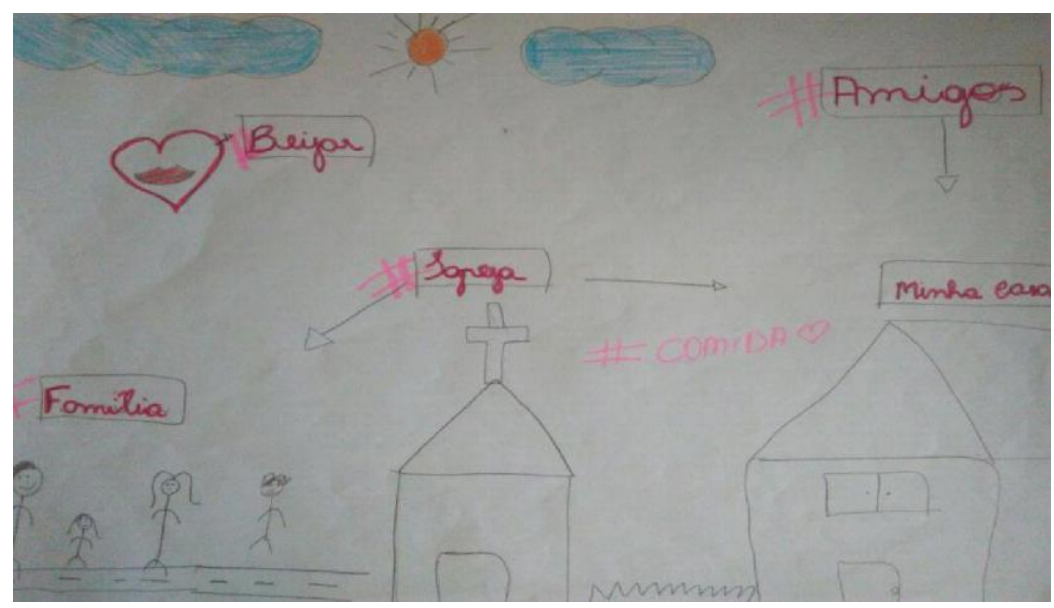

Figura 01

O segundo encontro ocorreu aos

14 dias de abril de 2016. Pretendeu-se trabalhar a percepção dos/as jovens participantes sobre o sentido de juventude considerando o olhar do outro, por meio da exposição de fotografias escolhidas aleatoriamente pelos/as pesquisadores/as. Chegou-se a um total de 09 (nove) fotos selecionadas, de pessoas ligadas in(diretamente) à orientadora e ao bolsista, desde amigos até contatos da rede social Facebook.

Durante as atividades foram lançadas perguntas norteadoras, com o objetivo de instigar e proporcionar discussões entre os/as jovens e com os/as pesquisadores/as. Essa atividade possibilitou identificar uma alta e complexa carga de opiniões préconcebidas nas falas dos/as estudantes. As imagens de pessoas negras (pretas ou 
pardas) apresentadas geralmente eram associadas à marginalidade. Tais ligações foram identificadas por meio de deduções como: "Parece bandido", "Deve ser traficante", "Cara de mau", "Cabelo pinga-creme", "Maconheiro".

No segundo momento foi solicitado que os/as jovens presentes produzissem um texto individual manuscrito, relatando seu cotidiano durante a semana, pontuando os locais mais frequentados, os caminhos percorridos e as atividades que desenvolviam em cada local. Após a conclusão, foi sugerida a socialização das produções, por meio da leitura voluntária. Os textos foram recolhidos pela equipe e utilizados como parte da metodologia de análise.

Por fim, foi requerido que os/as presentes fotografassem seu itinerário cotidiano durante uma semana e apresentassem as imagens no próximo encontro ao coletivo, potencializando as observações de seus cotidianos e ampliando o material analítico.

$\mathrm{O}$ terceiro encontro, realizado no dia 28 de abril de 2016, iniciou com destinação de cerca de quinze minutos para apresentação das fotos, seguido de debates e discussões. $\mathrm{O}$ encontro foi registrado em forma de vídeo e foi utilizado neste trabalho com o objetivo de confirmar falas e subsidiar as análises dos mapas mentais.

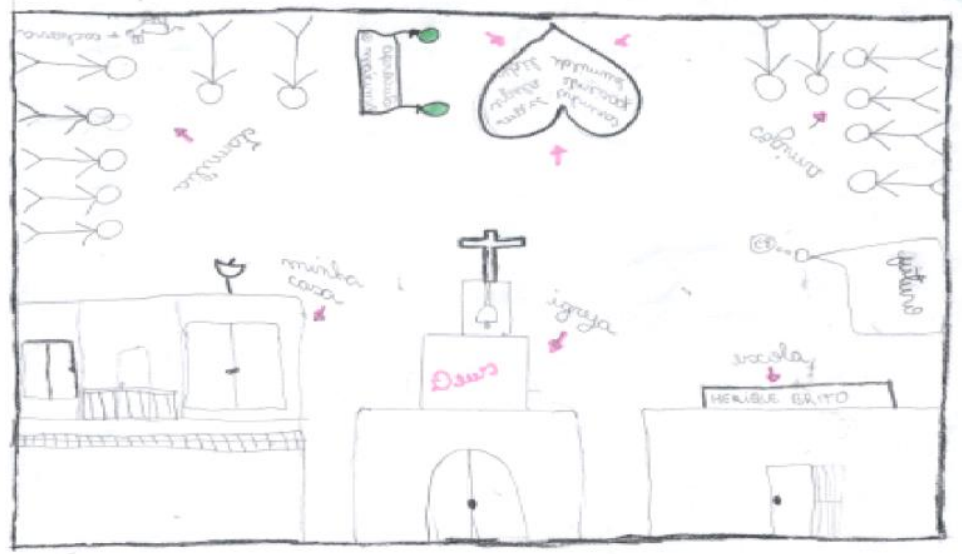


Breve introdução à Técnica dos

\section{Mapas Mentais}

Grosso modo, mapas mentais ou cognitivos são imagens espaciais que as pessoas têm de lugares conhecidos, direta ou indiretamente. De acordo com ARCHELA et.al. (2010: 127), “[...] as representações espaciais mentais podem ser do espaço vivido no cotidiano".

A ideia cartográfica conferida ao termo "mapa" - em um contexto em que a mente humana é o limite - dotado de "meridianos", de estrutura própria, mostra-se, a princípio, como área exclusiva das Ciências da Saúde. Ao refletir sobre as facetas da memória do indivíduo, sobretudo em seu espaçotempo, em sua vivência e apreensão de saberes e práticas, traduzidas em um papel, conclui-se a necessidade de estudar tal recurso a partir da posição das Ciências Humanas.

Para KOZEL (2009: 01), os mapas mentais "[...] podem ser construídos por intermédio de imagens, sons, formas, odores, sabores; logo, seu caráter significativo exige uma (ou mais) forma(s) de linguagem para ser comunicado". A autora entende os mapas mentais “[...] como uma forma de linguagem que retrata o espaço vivido representado em todas as suas nuances,
80

cujos signos são construções sociais". DEBARBIEUX (1998 apud KOZEL, 2010: 01) utiliza a terminologia “'representação' como processo pelo qual são construídas formas concretas ou idealizadas, dotadas de particularidades que podem também se referir a um outro objeto, fenômeno ou realidade".

Ainda sobre a importância dos mapas mentais como instrumento de análise, OLIVEIRA (2011: 03-04), apoiada em CAVALCATI (1998) argumenta que "[...] a partir de mapas mentais, podem-se conhecer os valores previamente desenvolvidos pelos alunos e avaliar a imagem que têm do seu lugar". Nesse direcionamento, MILGRAM e JODELET (1976 apud CRUZ; ARRUDA, 2008: 02) expõem que os mapas mentais “" [...] consistem em representações do espaço que possibilitam a localização espacial, mas que não são formadas meramente pela experiência pessoal e direta do sujeito com o ambiente".

O mapa mental, uma expressão do sensível, carrega consigo a formalidade da expressão territorial, nele, a pessoa se põe como elemento simbólico, ou seja, expõe seus símbolos internalizados. Os mapas mentais e as entrevistas mostraram o espaço construído: o lugar é formado pelos seres humanos e suas obras. [...] assim, todos os 
mapas mentais apresentados formam uma análise a respeito de um lugar visto através dos olhares dos próprios moradores e da sua vivência. Apontam um caminho para diversas interpretações e ao mesmo tempo, proporcionam uma observação sensível do lugar que está impregnado de elementos subjetivos presentes no seu cotidiano e se forem levados em conta nos planejamentos urbanos serão de grande valia para a implantação de diversas ações que revalorizem o lado humano da vida nas cidades. (LIMA; KOZEL, 2009: 227).

Em suma, podemos compreender a utilização de mapas mentais na metodologia científica como uma das possíveis formas de revelação da percepção do lugar vivido e forma de extração de memórias.

Operacionalmente, aplicamos a metodologia de Kozel para análise dos mapas mentais produzidos pelos participantes da pesquisa. Desse modo, o conteúdo dos mapas mentais deve ser analisado, considerando-se os seguintes aspectos:

1 - Interpretação quanto à forma de representação dos elementos na imagem (como ícones diversos, letras, mapas, linhas, figuras geométricas etc.);

2 - Interpretação quanto à distribuição dos elementos na imagem (as formas podem aparecer dispostas horizontalmente, de forma isolada, dispersa, em quadros em perspectiva etc.);
81

3 - Interpretação quanto à especificidade dos ícones:

Representação dos elementos da paisagem natural;

Representação dos elementos da paisagem construída;

Representação dos elementos móveis;

Representação dos elementos humanos;

4 - Apresentação de outros aspectos ou particularidades (KOZEL, 2007: 133) .

\section{Discussão dos Mapas Mentais produzidos pela juventude}

Como o trabalho realizado pretendeu angariar a percepção dos/as participantes sobre o território, foi necessário compreender como constroem as suas subjetividades. Para tanto, ancoramos a pesquisa nas noções de identidade de HALL (2006), notadamente em A Identidade Cultural na pós-modernidade, livro no qual o autor busca compreender e problematizar, identificar e ponderar as possibilidades de constituição das novas identidades, com base nas já existentes, avaliando o que a sociologia chama hoje de crise de identidade e quais as suas implicações nas sociedades contemporâneas.

Há conflitos evidentes no que diz respeito às questões de identidade. Percebe-se que as identidades sociais já 
constituídas estão cada vez mais fragmentadas, desestruturando as bases epistemológicas norteadoras dos seres humanos, o que possibilita pensar nas novas formulações identitárias. Nesse aspecto, é necessário pontuar três concepções distintas sobre identidade na perspectiva de HALL (2006: 10), quais sejam: a partir do Iluminismo, da Sociologia e da Pós-modernidade. As ideias iluministas compreendem a identidade como algo constitutivo e inerente aos seres humanos; já a Sociologia infere que as identidades são construídas por meio das relações sociais, ao passo que a concepção pósmoderna compreende a identidade como mutável, afixo, que possui um sistema contínuo de inferências internas - sujeito - e externas - sociedade, superando a concepção biológica, pois passa a ser vista a partir do crivo das Ciências Sociais.
A partir desse pensamento, as percepções identitárias são concebidas como variáveis e temporárias, pois dependem de inúmeros sistemas de significações e representações culturais e sociais.

Dito isto, para a elaboração deste trabalho, selecionamos 3 (três) mapas mentais dentre os 18 produzidos pelo grupo, a partir de critérios específicos, como: qualidade visual das representações, quantidade de elementos representados e diversidade de elementos simbólicos. Como procedimento metodológico, optamos pela descrição seguida de análise. Ao fazer tal escolha, consideramos a necessidade de identificar e analisar cada elemento representado, a fim de entender as relações com os sujeitos da pesquisa.

Para a obtenção dos mapas mentais, lançou-se uma pergunta central: "Como é ser jovem na cidade de Teixeira de Freitas? ". 


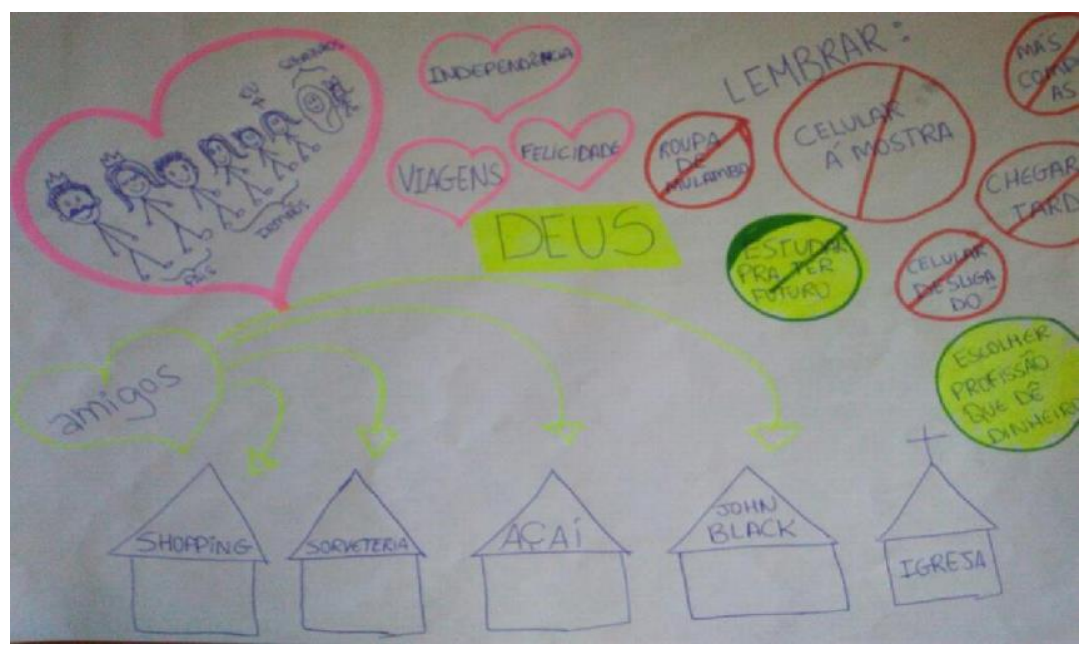

\section{Figura 03}

Abaixo, descrevemos as etapas da leitura dos mapas:

Fase 1- Interpretação quanto à forma de representação dos elementos na imagem

Em todos os mapas, foi identificada a combinação entre ícones, setas de indicação, pequenos retângulos, figuras e letras que apareceram nos desenhos em diversas formas, tamanhos e posições. Os termos ou palavras mais utilizados foram "Deus" (em 10 mapas de um total de 18) e "Família" (em 10 mapas de um total de 18). Quanto à nomeação dos espaços ou lugares: Igreja (em 15 mapas de um total de 18), "Casa" (em 10 mapas de um total de 18),
"Escola ou Colégio" (em 6 mapas de um total de 18), "Praças, Shoppings, Casas noturnas" (em 6 mapas de um total de 18).

As principais expressões foram: "Aproveite o máximo" (em 1 de um total de 18 mapas), "É preciso amar como se não houvesse amanhã!!" e "Por isso viva!! Deus" (em 1 de um total de 18 mapas ), "Foco na profissão futura" (em 1 de um total de 18 mapas).

Fase 2 - Interpretação quanto à distribuição dos elementos na imagem

Os elementos representativos estão dispostos na horizontalidade, de forma harmônica (em 17 de um total de 18 mapas); alguns mapas apresentam os 
elementos em forma de organograma, interligado por setas de indicação e identificados com nomes (em 4 de um total de 18 mapas); houve os que mesclaram o organograma com as representações por meio de figuras (em 1 de um total de 18 mapas ) e, por fim, houve representação disposta na vertical (em 1 de um total de 18 mapas).

Fase 3 - Interpretação quanto à especificidade dos ícones/representação dos elementos: da paisagem natural; da paisagem construída; móveis e humano

Elementos móveis como carros, bicicletas, transporte público, motos, etc., não foram representados pelo grupo. Acreditamos que isso denota a não compreensão total do espaço e do território vivido pelos sujeitos da pesquisa, ao menos no momento de produzir os mapas. Talvez isso se deva ao modo como foi explicada a atividade, pois, como se tratou de um trabalho sobre percepção e território, entendido de modo mais restrito, os/as participantes compreenderam que se tratava da sua vida cotidiana, para onde se deslocam na vida de todos os dias, não em momentos extraordinários.

Observa-se que alguns mapas apresentam ícones tipicamente compostos por elementos correspondentes à paisagem construída, como sorveterias, praças e centros de compras (em 7 mapas de um total de 18). Elementos humanos aparecem em diversos mapas, sempre representando laços diretos com os sujeitos da pesquisa, como familiares e amigos (em 11 mapas de um total de 18); alguns apresentam elementos de paisagens naturais (em 3 mapas de um total de 18).

Fase 4 - Apresentação de outros aspectos ou particularidades:

$\mathrm{Na}$ perspectiva das relações estabelecidas pelos sujeitos observou-se, tanto nos textos escritos quanto na leitura dos mapas, que os/as estudantes preocupam-se muito com o futuro, mais especificamente, com a situação pósensino médio, na busca pela independência, trabalho (em 5 de um total de 18 mapas). Para uma análise mais minuciosa, apresenta-se abaixo a interpretação referente aos 3 (três) mapas escolhidos entre os 18 (dezoito) produzidos pelos membros do grupo.

\section{Figura 1. Mapa Mental produzido por} V.S. 16 anos:

O mapa apresenta elementos de paisagem natural e 
construída (nuvens, sol, igreja, casa), ícones juvenis que devem estar presentes na vivência da autora como, por exemplo, o gosto por afeto, pelo beijo, pelas amizades. Exprime vínculo religioso, o que possivelmente se interliga ao lar e à família, pois houve cuidado da autora em centralizar a representação da igreja e, ao seu lado, alocar a representação de sua casa e, do outro lado, representar sua família. As ligações foram sinalizadas por meio de setas. As representações estão expostas de forma harmônica, o que denota cuidado ao demonstrar os elementos.

\section{Figura 2. Mapa Mental produzido por}

\section{A.S. 16 anos, $3^{\circ}$ Ano:}

No centro do mapa há a representação de uma igreja, contendo ao seu lado esquerdo a representação de uma casa e, do lado direito, o colégio. Vale ressaltar que é o único mapa que representa o colégio, identificando-o pelo nome. O mapa apresenta delineação de espaço representado por um retângulo que demarca as margens da representação, o que denota preocupação e cuidado em sua elaboração, contendo a representação humana pela identificação dos membros da família. Há preocupação em aproveitar a vida, gozando da liberdade e usufruindo do afeto, com preocupação consigo e com respeito aos outros. Apesar dessa liberdade e vontade de viver $o$ momentâneo, os questionamentos com relação ao futuro estão presentes e bem representados em uma caixa de pensamento seguida da palavra "Futuro".

\section{Figura 3. Mapa Mental produzido por} N.S. 16 anos:

O mapa de número 3 (três) é bem interessante e contributivo para este trabalho, considerando-se a inserção de vários temas em um único espaço. Este mapa possui elementos de natureza construída, representando locais e espaços frequentados pela autora, como sorveteria, boate, centro de compras e igreja, todos locais interligados com setas de indicação ao grupo de pessoas representado como "amigo". Um outro grupo representado neste mapa mental é a família, cuja representação mescla jovialidade e traços de desenho "infantil", pois as figuras possuem coroas e são identificadas pelas legendas "Pais, Irmãos, Eu, Sobrinhos". Em caixas de pensamento em formato de balões, no canto superior do mapa, são 
apresentados alguns possíveis desejos da jovem, como: a busca pela felicidade, independência, viagens e a representação de sua fé por meio do nome em destaque "Deus". Uma situação que chama atenção nesta representação é a presença da palavra "Lembrar", seguida de inúmeras recomendações, tais como: "Estudar para ter futuro", "Escolher uma profissão que dê dinheiro", seguido de diversas proibições como: "Roupa de mulambo", fazendo uma analogia às roupas em desuso ou gastas; outras proibições são "Celular à mostra", "Más companhias", "Chegar tarde", "Celular desligado".

Em diálogos durante as oficinas, os/as jovens relataram que a cidade onde vivem é perigosa e que evitar o uso de celular na rua, por exemplo, é um mecanismo de segurança.

As construções dos mapas mentais aliados à observação participante constataram que os sujeitos da pesquisa têm a religião como fonte de lazer, possuem restrições de mobilidade territorial, advinda do medo da violência urbana, muitas das vezes enfatizada de forma perversa pelos meios de comunicação regional - sites, rádios, tevê -, o que favorece hábitos de vida sedentários. Utilizam bastante as redes sociais, têm grande preocupação com o futuro, principalmente no que diz respeito à estabilidade financeira $\mathrm{e}$ social, o que pôde ser observado pela frase apresentada no mapa mental de número 3: "Escolher uma profissão que dê dinheiro".

\section{Considerações Finais}

Com a realização deste trabalho, buscou-se compreender de que modos os/as jovens de diferentes bairros de Teixeira de Freitas constroem a (auto)imagem geracional através da técnica dos mapas mentais, baseando-se em sua visão de mundo em relação à cidade e ao seu lugar no espaço urbano e social. Nesse sentido, o problema da pesquisa efetivou-se a partir do questionamento sobre os modos como os/as jovens moradores/as de diferentes bairros da cidade de Teixeira de Freitas/BA constroem suas subjetividades em relação ao espaço urbano e como elaboram discursivamente a alteridade com outros/as jovens que não circulam - ou que não deveriam circular, pela lógica excludente e marginalizante das classes médias - pelos mesmos espaços físicos e, consequentemente, sociais, a não ser 
como "tumultuadores" ou agentes de violência.

Observou-se que os/as jovens participantes veem os outros assim, como potenciais criminosos, mas não eles/as próprios/as que, em sua maioria, são moradores/as de periferias. Por exemplo: assaltantes são sempre jovens, na opinião deles, mas "jovens que não têm Deus". São pessoas de outras localidades, bairros periféricos e distante dos bairros próximos ao centro econômico da cidade, que saem com o objetivo de roubar, o que pode ser corroborado pelo levantamento bibliográfico realizado durante a pesquisa:

Tradicionalmente, a violência costuma ser relacionada à pobreza, à exclusão social, à omissão do Estado, ausência de serviços públicos urbanos e ao próprio processo de urbanização que cria os enclaves de pobreza e as periferias. A complexidade e o crescimento da violência nas cidades tem levado a considerá-la como o resultado da junção de todos esses aspectos, facetas do processo social. (FERREIRA; PENNA, 2011: 157).

Dito isto, compreende-se que os sujeitos da pesquisa sentem seu espaço de circulação pela cidade reduzido, também em relação a determinados horários, em razão do medo social, que se alastra nas falas cotidianas e nas publicações midiáticas locais e regionais. Ou seja, trata-se da percepção da cidade como lugar topofóbico, do qual se deve criar estratégias de proteção.

Como técnica de análise, foi empregada a dos mapas mentais ou cognitivos que, a partir de desenhos elaborados pelos sujeitos de pesquisa, permitiram derivar dados e informações para a reelaboração do que havia sido planejado para as oficinas. Os mapas desenvolvidos pelos sujeitos participantes podem ser considerados mais uma dentre tantas outras possibilidades para compreender a percepção das pessoas sobre o espaço físico e social onde residem. Deriva da trajetória desta pesquisa a impressão de que entrevistas individuais poderiam agregar mais informações e revelar contradições com os momentos coletivos.

Os levantamentos e problematizações aqui realizadas apontaram para um dentre tantos outros caminhos. Ao final, concluímos que a juventude teixeirense cuja produção foi analisada entende e vive de forma segregatória os espaços abrangidos pelo território, seja com base nos índices de violência que insistem em permear as 


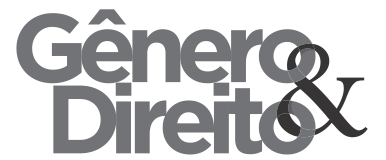

Periódico do Núcleo de Estudos e Pesquisas sobre Gênero e Direito

Centro de Ciências Jurídicas - Universidade Federal da Paraíba

V. 8 - $\mathrm{N}^{\circ} 05$ - Ano 2019

ISSN | 2179-7137 | http://periodicos.ufpb.br/ojs2/index.php/ged/index relações sociais, criando entre os possíveis diálogos sociais ruídos, seja por experiências pregressas que vivenciaram. Observou-se que os/as jovens têm uma visão problemática com relação à juventude residente nos diferentes bairros da cidade, muitas das vezes associando os/as outros/as com quem nao convivem ao tráfico de drogas, condicionando-as/as a uma vida marginal, fora do alcance do Estado, a partir da repetição de termos como "marginais", "vagabundos", "bandidos". Resulta também da pesquisa a ideia de que a violência é atribuída eminentemente a jovens homens.

\section{Referências Bibliográficas}

Archela, Rosely Sampaio; Gratão, Lucia Helena B.; Trostdorf, Maria A.S, 2010. O lugar dos mapas mentais na representação do lugar. GEOGRAFIA. Londrina, v. 13, n. 1, p. 127-142.

Andrade, José Eduardo de; Rodrigues, Júlia Alves Marinho, 2008. Ação pública para a juventude. Cadernos Cenpec. Nova série, v. 3, n. 5.

Cury, Beto, 2009. Os muitos desafios da política nacional de juventude. In:
Avritzer, Leonardo (org.). Experiências nacionais de participação social. São Paulo: Cortez.

Cruz, Ana Carolina Dias; Arruda, Angela, 2008. Por um estudo do ausente: a ausência como objetivação da alteridade em mapas mentais do Brasil. Estudos e Pesquisas em Psicologia, v. 8, n. 3 .

Ferreira, Ignez Ferreira Costa Barbosa; Penna, Nelba Azevedo, 2011. Território da violência: um olhar geográfico sobre a violência urbana. GEOUSP: espaço e tempo, n. 18, p. 155-168. Disponível eh:<http://www.revistas.usp.br/geousp Larticle/view/73979>. Acessado em: maio de 2016.

Flick, Uwe, 2009. Introdução à Pesquisa Qualitativa. Tradução. Joice Elias Costa. 3.ed. Porto Alegre, RS: Artmed.

Hall, Stuart, 2006. A identidade cultural na pós-modernidade. Tradução Tomaz Tadeu da Silva, Guacira Lopes Louro 11. ed - Rio de Janeiro: DP\&A.

Kozel, Salete, 2016. As linguagens do cotidiano como representações: uma proposta metodológica possível. Disponível em:< 
http://observatoriogeograficoamericalati na.org.mx/egal12/Teoriaymetodo/Meto dologicos/04.pdf>. Acesso em: maio de 2016.

, 2010 .Representação do espaço sob a ótica, dos conceitos: mundo vivido e dialogismo. Anais do Encontro nacional de Geógrafos. Porto Alegre. 2007. Mapas mentais - uma forma de linguagem: perspectivas metodológicas. In: Costa e Silva, J.; Gil Filho, S. F. (orgs.). Da Percepção e cognição à representação:Reconstruções teóricas da Geografia Cultural e Humanista. São Paulo: Terceira Margem, 2007. p.114-138.

Koopmans, José, 2006. Além do eucalipto: o papel no Extremo Sul. Cadernos do CEA - Revista Crítica de Humanidades. UCSAL, Salvador. Disponível em: https://cadernosdoceas.ucsal.br/index.ph p/cadernosdoceas/article/view/180

Acesso em 20 de janeiro de 2018.

Lima, Angélica Macedo Lozano; Kozel, Salete, 2009. Lugar e mapa mental: uma análise possível. GEOGRAFIA, Londrina, v. 18, n. 1, p. 207-231.
Oliveira, Nilza. A. S. Mapas Mentais, 2007. Uma forma de representar a compreensão e interpretação do lugar. Disponível em: $<$ http://www.neer.com.br/anais/NEER2/Trabalhos_NEER/Ordemalfabetica/M icrosoft $\% 20$ Word\%20\%20NilzaApdaSilvaOliveira.ED2I.b.pd f $>$. Acesso em: maio de 2016

Raffestin, Claude, 1993. Por uma geografia do poder. Tradução de Maria Cecília França. São Paulo: Ática.

Rocha, Daniel, 2015. Alguns fatos históricos da cidade de Teixeira de Freitas. Disponível em: $<$ http://www.teixeiradefreitas.ba.gov.br/ n/?page $i d=348>$. Acesso em: maio de 2016.

Santos, Milton, 1978. Por uma Geografia Nova. São Paulo: Hucitec/Edusp.

Tuan, Yi-Tu, 1980. Topofilia - um estudo da percepção, atitudes e valores do meio ambiente. São Paulo, Rio de Janeiro: Difel 